\title{
Dynamic DNA methylation of matrix metalloproteinase-9 in the development of diabetic retinopathy
}

\author{
Renu A Kowluru, Yang Shan and Manish Mishra
}

Diabetes elevates matrix metalloproteinase-9 (MMP-9) in the retina and its capillary cells, and activated MMP-9 damages mitochondria, accelerating retinal capillary cell apoptosis, a phenomenon which precedes the development of retinopathy. Diabetes also favors epigenetic modifications regulating the expression of many genes. DNA methylation is maintained by methylating-hydroxymethylating enzymes, and retinal DNA methyltransferase (Dnmt) is activated in diabetes. Our aim is to investigate the role of DNA methylation in MMP-9 regulation. The effect of high glucose on 5-methylcytosine $(5 \mathrm{mC})$ and 5-hydroxymethyl cytosine $(5 \mathrm{hmC})$, and binding of Dnmt1 and hydroxymethylating enzyme (Tet2) on MMP-9 promoter were quantified in retinal endothelial cells. Specific role of Tet2 in MMP-9 activation was validated using Tet2-siRNA. The results were confirmed in the retina from streptozotocin-induced diabetic mouse. Although glucose increased Dnmt1 binding at MMP-9 promoter, it decreased $5 \mathrm{mC}$ levels. At the same promoter site, Tet2 binding and $5 \mathrm{hmC}$ levels were elevated. Tet2-siRNA ameliorated increase in $5 \mathrm{hmC}$ and MMP-9 transcription, and protected mitochondrial damage. Diabetic mice also presented similar dynamic DNA methylation changes in the retinal MMP-9 promoter. Thus, in diabetes transcription of retinal MMP-9 is maintained, in part, by an active DNA methylation-hydroxymethylation process, and regulation of this machinery should help maintain mitochondrial homeostasis and inhibit the development/progression of diabetic retinopathy.

Laboratory Investigation (2016) 96, 1040-1049; doi:10.1038/labinvest.2016.78; published online 25 July 2016

Diabetic retinopathy remains one of the major causes of blindness in working adults. Many diabetes-mediated retinal metabolic abnormalities are implicated in its development, but the pathogenesis of this progressing disease remains complex. Our previous work has documented that diabetes activates retinal gelatinase matrix metalloproteinases (MMPs), and activated MMPs damage the mitochondria. The damaged mitochondria allow cytochrome $C$ to leak into the cytosol, initiating apoptosis of capillary cells, ${ }^{1-6}$ a phenomenon that is followed by the histopathology associated with diabetic retinopathy. ${ }^{7}$

Transcription of MMP-9 gene is regulated by upstream sequences, which contain motifs with binding sites for transcriptional factors including $\mathrm{NF}-\kappa \mathrm{B}$ and $\mathrm{AP}-1 .{ }^{8}$ In diabetes, $M M P-9$ transcription is upregulated in the retina and its capillary cells, and the binding of transcriptional factors NF- $\kappa \mathrm{B}$ and $\mathrm{AP}-1$ is increased at its promoter. ${ }^{9}$ In addition to transcription factors, gene expression is also regulated by epigenetic modifications, and diabetes induces many such epigenetic modifications including DNA methylation and histone methylation/acetylation. ${ }^{3,10,11}$ Methylation of the fifth carbon of cytosine (5-methylcytosine, $5 \mathrm{mC}$ ) in the promoter or other upstream regulatory regions of a gene is generally associated with impaired binding of the transcription factors and repressed gene expression. ${ }^{12,13}$ Although DNA methylation is necessary for establishment and maturation of cell fates, ${ }^{14}$ and hypermethylation of retinal neurons onsets their programmed cell death, ${ }^{15}$ aberrant DNA methylation is associated with many chronic diseases including cancer, diabetes, age-related macular degeneration and diabetic retinopathy. ${ }^{12,13,16-18}$ In diabetes, retinal mitochondrial DNA (mtDNA) and the gene encoding the enzyme responsible for mtDNA biogenesis, polymerase $\gamma 1$, are hypermethylated compromising the electron transport chain machinery and mtDNA biogenesis. ${ }^{19,20}$

DNA methylation is catalyzed by DNA methyltransferases (Dnmts); Dnmt3a and 3b are de novo enzymes, and Dnmt1 is a maintenance enzyme important in regulating tissue-specific patterns of the methylated cytosine. ${ }^{21,22}$ In diabetes, Dnmt activity is increased and the expression of Dnmt1 is elevated in the retina and its capillary cells. ${ }^{20}$ Methylation of DNA is dynamically regulated both through passive and active

Department of Ophthalmology, Kresge Eye Institute, Wayne State University, Detroit, MI, USA

Correspondence: Dr RA Kowluru, PhD, Department of Ophthalmology, Kresge Eye Institute, Wayne State University, 4717 St Antoine, Detroit, MI 48201 , USA.

E-mail: rkowluru@med.wayne.edu

Received 22 April 2016; revised 13 June 2016; accepted 19 June 2016 
Table 1 Primer sequences

\begin{tabular}{|c|c|c|}
\hline Gene & Sequence $\left(5^{\prime}-3^{\prime}\right)$ & $\begin{array}{l}\text { Ampicon } \\
\text { lengh (bp }\end{array}$ \\
\hline \multicolumn{3}{|l|}{ Bovine } \\
\hline MMP-9 promoter & CAGACGCCACAACACTCCCA & 174 \\
\hline$(-720$ to -547$)$ & TCCTCTCCCTGCTCCACCTG & \\
\hline MMP-9 CGl & TCTCTTGCCTGTCTCTGAA & 215 \\
\hline$(1487-1701)$ & CATCTCCGTGCTCTGAAG & \\
\hline \multirow[t]{2}{*}{ Dnmt1 } & ACCATGTCTGACCTCCCTGA & 149 \\
\hline & GCGCTCATGTCCTTGCAAAT & \\
\hline \multirow[t]{2}{*}{ Tet1 } & ACACAATGACAGATGGCTTCTT & 196 \\
\hline & АССТСТTСТССТTССТACACAA & \\
\hline \multirow[t]{2}{*}{ Tet2 } & GTGAGGGTGCATACCAGTGT & 89 \\
\hline & GTCTGGGTCTGAAGGAAGGC & \\
\hline \multirow[t]{2}{*}{ Tet3 } & TCAAGTCTGTGGTCGTGGAG & 265 \\
\hline & GAGGTGGCGTGAGAAGGTT & \\
\hline \multirow[t]{2}{*}{ Cytb } & CGATACATACACGCAAACGG & 298 \\
\hline & AGAATCGGGTAAGGGTTGCT & \\
\hline \multirow[t]{2}{*}{ ND6 } & CGTGATAGGTITTGTGGGGT & 221 \\
\hline & GCCAGTAACAAATGCCCCTA & \\
\hline \multirow[t]{2}{*}{$\beta$-actin } & CGCCATGGATGATGATATTGC & 66 \\
\hline & AAGCCGGCCTTGCACAT & \\
\hline \multicolumn{3}{|l|}{ Mouse } \\
\hline MMP-9 promoter & CTAGCCTGAGAAGGATGAAG & 285 \\
\hline$(-640$ to -356$)$ & TTCCTTGGGCTTCTGAGA & \\
\hline MMP-9 CGl & GTCGCAGTCACCTCTTCTCA & 240 \\
\hline$(1361-1600)$ & ACCACAACTCGTCGTCGTC & \\
\hline \multirow[t]{2}{*}{ Dnmt1 } & CCTAGTTCCGTGGCTACGAGGAGAA & 137 \\
\hline & TCTCTCTCCTCTGCAGCCGACTCA & \\
\hline \multirow[t]{2}{*}{ Dnmt3a } & GCCGAATTGTGTCTTGGTGGATGACA & 147 \\
\hline & CCTGGTGGAATGCACTGCAGAAGGA & \\
\hline \multirow[t]{2}{*}{ Dnmt3b } & GTCTGCACACCAGAGACCAGAG & 140 \\
\hline & TCAGAGCCATTCCCATCATCTAC & \\
\hline \multirow[t]{2}{*}{ Tet1 } & GAGCCTGTTCCTCGATGTGG & 256 \\
\hline & CAAACCCACCTGAGGCTGTT & \\
\hline \multirow[t]{2}{*}{ Tet2 } & TGTTGTTGTCAGGGTGAGAATC & 103 \\
\hline & TCTTGCTTCTGGCAAACTTACA & \\
\hline \multirow[t]{2}{*}{ Tet3 } & CCGGATTGAGAAGGTCATCTAC & 162 \\
\hline & AAGATAACAATCACGGCGTTCT & \\
\hline \multirow[t]{2}{*}{$\beta$-actin } & CCTCTATGCCAACACAGTGC & 215 \\
\hline & CATCGTACTCCTGCTTGCTG & \\
\hline
\end{tabular}

mechanisms; while passive DNA demethylation is mostly found in mitotic cells, active demethylation, in which oxidation of $5 \mathrm{mC}$ forms 5-hydroxymethylcytosine (5hmC), is mediated by ten-eleven translocation enzymes (Tets). ${ }^{23-25}$ Hyperglycemic milieu activates Tets in zebrafish inducing a genome-wide demethylation and aberrant gene expression. ${ }^{26}$ However, how altered DNA methylation machinery contributes to the development of diabetic retinopathy is unclear.

Although the promoter region of MMP-9 has relatively few CpG sites, DNA methylation is shown to modulate its transcription. ${ }^{27,28}$ The aim of this study is to investigate the dynamic DNA methylation of MMP-9 promoter in the development of diabetic retinopathy. Using retinal endothelial cells, one of the target cells of retinal histopathology characteristic of diabetic retinopathy, we investigated the effect of $20 \mathrm{mM}$ D-glucose on the methylation-hydroxymethylation status of MMP-9 promoter. The specific role of the DNA methylation-hydroxymethylation was determined by regulating these enzymes by their specific siRNA, and the in vitro results were confirmed in the retina from diabetic mice.

\section{MATERIALS AND METHODS Retinal Endothelial Cells}

Retinal endothelial cells, prepared from bovine eyes, from 4th to 7 th passage were incubated in normal $(5 \mathrm{mM})$ or high (20 mM) D-glucose for 4 days, and parallel osmotic controls included cells incubated in $20 \mathrm{mM}$ mannitol or $20 \mathrm{mM}$ L-glucose. ${ }^{9,20}$ To investigate the effect of inhibition of Tet in demethylation of MMP-9 promoter, a batch of cells were incubated with a cell-permeable inhibitor (2S)-octyl- $\alpha$ hydroxyglutarate (2-HG, $500 \mu \mathrm{M}$; Cayman, Ann Arbor, MI, USA). ${ }^{29}$ The cells received fresh media, including 2-HG, every $24 \mathrm{~h}$. Inhibition of Dnmts/Tets was further confirmed by transfecting the cells with their specific siRNAs (Dnmt1siRNA (Santa Cruz Biotechnology, Santa Cruz, CA, USA) and Tet2-siRNA (Integrative DNA Technology, Coralville, IA, USA)) using Lipofectamine RNAiMAX transfection reagent (Thermo Fisher Scientific, Rockford, IL, USA), as routinely performed in our laboratory. ${ }^{9,20}$ Parallel incubations with non-targeting scrambled RNA were used as transfection controls. After transfection, the cells were rinsed and incubated in either 5 or $20 \mathrm{mM}$ D-glucose media for 4 days. The efficiency of transfection was determined by quantifying their protein (western blot) and gene (SYBR Green-based quantitative real-time PCR (qPCR)) expressions.

\section{Animal Models}

Eight-week-old C57BL/6J mice were randomly assigned to normal and diabetes group. Diabetes was induced by streptozotocin (intraperitoneally; $55 \mathrm{mg} / \mathrm{kg} \mathrm{BW}$ ) for 4 consecutive days, and 2 days after the last injection, animals presenting blood glucose over $250 \mathrm{mg} / \mathrm{dl}$ were considered as diabetic. Animals in the diabetic group received daily insulin injection (0.1-0.3 IU, NPH) to prevent weight loss and dehydration. The mice were killed 6 months after induction of diabetes by using carbon dioxide, and retina were collected 

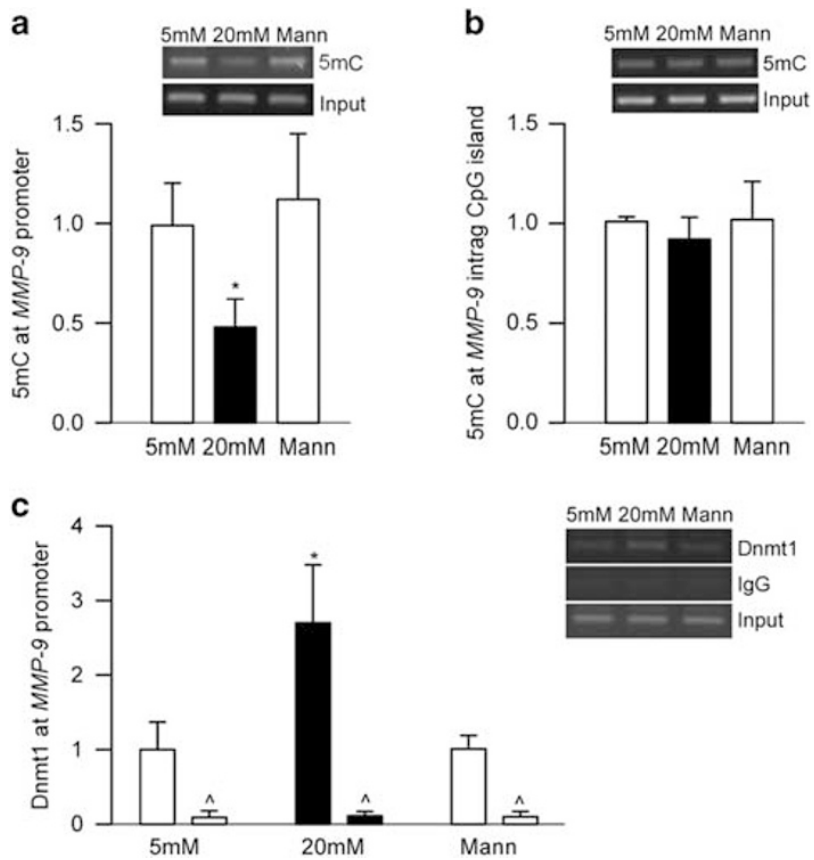

Figure 1 High D-glucose hypomethylates matrix metalloproteinase-9 (MMP-9) promoter in retinal endothelial cells, and increases DNA methyltransferase 1 (Dnmt1) binding at the same region of the promoter. The levels of 5-methylcytosine $(5 \mathrm{mC})$ were quantified in retinal endothelial cells by methylated DNA Immunoprecipitation Kit from EpiGentek, and primers for (a) promoter region $(-720$ to -547$)$, and (b) intragenic CpG island region (1487-1701) of MMP-9 gene. The total genomic DNA from cells in $5 \mathrm{mM}$ glucose served as an input DNA control. (c) Dnmt1 binding at the MMP-9 promoter was quantified using Dnmt1 monoclonal antibody, followed by amplification of the promoter region by quantitative real-time PCR (qPCR). Immunoglobulin $\mathrm{G}(\mathrm{lgG})$ was used as a negative antibody control (indicated as $\wedge$ ), and $\mathrm{Ct}$ values were normalized with the values from input by ddCt method. Product size was confirmed on an agarose gel. Values are represented as mean \pm s.d. from four to five samples in each group. Five and $20 \mathrm{mM}=5$ or $20 \mathrm{mM}$ D-glucose, Mann $=20 \mathrm{mM}$ mannitol. ${ }^{*} P<0.05$ compared with $5 \mathrm{mM}$ D-glucose.

immediately. Age-matched, nondiabetic mice served as controls. These procedures conformed to the Association for Research in Vision and Ophthalmology Resolution on the Use of Animals in Research and are approved by our Institutional Animal Care and Use Committee, and are routinely used in our laboratory. ${ }^{2,4}$

\section{Chromatin Immunoprecipitation}

To analyze potential interactions between DNA and epigenetic machinery, chromatin immunoprecipitation (ChIP) assay was performed using the methods routinely performed in our laboratory. ${ }^{9,20}$ Briefly, paraformaldehyde crosslinked samples were sonicated six times for $10 \mathrm{~s}$ each using a Sonic Dismembrator (Model 100; Thermo Fisher Scientific) at a setting 6 for retina and 4 for endothelial cells. The samples were then diluted in ChIP dilution buffer and precleared with protein A agarose/salmon sperm DNA (EMD Millipore,
Billerica, MA, ISA) for $1 \mathrm{~h}$ at $4{ }^{\circ} \mathrm{C}$. This was followed by overnight incubation of $100-120 \mu \mathrm{g}$ sample with Dnmtl or Tet2 antibodies (Dnmt1, cat. no. ab13537 and Tet2, cat. no. ab135087; Abcam, Cambridge, MA, USA). The antibodychromatin complexes were pulled down with protein A/G agarose beads and washed extensively before eluting with $1 \%$ SDS and $0.1 \mathrm{M} \mathrm{NaHCO}$. Protein-associated DNA was recovered by incubation at $65^{\circ} \mathrm{C}$ overnight, and then purified by phenol extraction. Purified DNA was precipitated with ethanol, resuspended in water, and used for $\mathrm{qPCR}$ using primers of the regions of interest. Normal rabbit IgG (cat. no. 2729S; Cell Signaling, Danvers, MA, USA) was used as a negative antibody control, and DNA from the input $(40 \mu \mathrm{g}$ protein-DNA complex) as an internal control. The specificity of ChIP assay was confirmed by analyzing the products on a $2 \%$ agarose gel, and representative gel images are included in the accompanying figures.

\section{Quantification of $5 \mathrm{mC}$ and $5 \mathrm{hmC}$}

Sonicated DNA was immunoprecipitated for $5 \mathrm{mC} / 5 \mathrm{hmC}$ using methylated/hydroxymethylated DNA Immunoprecipitation (MeDIP/hMeDIP) Kits (EPIGENTEK, Farmingdale, NY, USA). The enriched $5 \mathrm{mC} / 5 \mathrm{hmC}$ fractions were analyzed by qPCR using species-specific MMP-9 primers (Table 1), as recently reported by us. ${ }^{20}$ The products were confirmed by semiquantitative PCR on a $2 \%$ agarose gel.

\section{Western Blot}

Protein $(30-40 \mu \mathrm{g})$ was separated on a $4-20 \%$ gradient acrylamide gel (Bio-Rad, Hercules, CA, USA). The proteins transferred onto nitrocellulose membranes were detected using antibodies against the proteins of interest (Dnmtl and Tet2 from Abcam, and $\beta$-actin cat. no. A-5316 from SigmaAldrich, St Louis, MO, USA). Images were quantified by the Carestream MI software (Carestream, Rochester, NY, USA), and the intensities of the target bands were normalized to those of the loading control, $\beta$-actin.

\section{Gene Transcripts}

Gene transcripts were quantified by qPCR using targetspecific primers. Amplification program included the holding stage at $50^{\circ} \mathrm{C}$ for $2 \mathrm{~min}$ and $95^{\circ} \mathrm{C}$ for $10 \mathrm{~min}$, followed by 40 cycles of denaturation at $95^{\circ} \mathrm{C}$ for $15 \mathrm{~s}$, annealing and extension at $60^{\circ} \mathrm{C}$ for $1 \mathrm{~min}$, and $72^{\circ} \mathrm{C}$ for $5 \mathrm{~min}$. Reaction specificity was validated by a single peak in the melting curve. For MMP-9, TaqMan qPCR was performed. Values of the products were normalized to the cycle threshold $(\mathrm{Ct})$ value from the input sample, and those in cDNA were normalized to the $\mathrm{Ct}$ values from $\beta$-actin in the same sample. Relative fold changes were calculated by considering the values obtained from cells in $5 \mathrm{mM}$ glucose or normal mice as one. ${ }^{4,9,20}$

\section{Enzyme Activities of Dnmt and Tet}

The global activities of Dnmt and Tet were determined in nuclear fractions using EpiQuik DNA Methyltransferase 
Activity/Inhibition and Epigenase 5mC-Hydroxylase TET Activity/Inhibition Assay Kits (EpiGentek), respectively. Briefly, nuclear extracts (3-6 $\mu$ g for Dnmt or $10-20 \mu \mathrm{g}$ for Tet activity) was added to the microplates coated with enzyme substrates, and the reaction products were detected by following the manufacturer's instructions.

\section{Mitochondrial Damage}

Mitochondrial damage was evaluated by quantifying the gene transcripts of mtDNA-encoded cytochrome b (Cytb) of complex III and ND6 of complex I, as reported previously. $4,9,20$

\section{Statistical Analysis}

Results were analyzed using SigmaPlot (Systat, Chicago, IL, USA), and the data are presented as mean \pm standard deviations. Statistical test between two groups was carried out by $t$-test or Mann-Whitney rank-sum test. For multiple comparisons for the data with normal distribution, one-way ANOVA followed by Student-Newman-Keuls test was performed, and for the data that did not qualify the normal distribution pattern, one-way analysis on ranks followed by Dunn's test were used. A $P$-value $<0.05$ was considered as statistically significant.

\section{RESULTS}

\section{Retinal Endothelial Cells}

Incubation of retinal endothelial cells in $20 \mathrm{mM}$ D-glucose resulted in $\sim 50 \%$ reduction in $5 \mathrm{mC}$ levels in MMP-9 promoter $(-720$ to -547$)$ compared with the cells incubated in normal glucose or $20 \mathrm{mM}$ mannitol (Figure 1a). In contrast, in the intragenic (1487-1701) CpG island region of the MMP-9 gene, $5 \mathrm{mC}$ values were similar in the cells incubated in normal or high D-glucose (Figure 1b).

Since Dnmt plays a major role in the formation of $5 \mathrm{mC}$, and among its 3 major isoforms, hyperglycemia increases Dnmt1 transcripts in retinal endothelial cells, ${ }^{20}$ the binding of Dnmt1 at MMP-9 promoter was determined by ChIP technique. Contrary to a significant decrease in $5 \mathrm{mC}$ levels, high D-glucose increased Dnmtl binding by over 2.5-fold, suggesting an active methylation-demethylation processes. Values obtained from IgG controls were less than 1\% compared to the values obtained using Dnmtl antibody (Figure 1c).

To further confirm the role of Dnmt1 in the methylation status of MMP-9 promoter, cells transfected with Dnmt1siRNA were utilized. Transfection of cells with Dnmt1-siRNA significantly decreased $5 \mathrm{mC}$ levels, and the values obtained from Dnmt1-siRNA-transfected cells incubated in normal or high D-glucose were not significantly different from the untransfected cells in high D-glucose (Figure 2a). Figures 2b and $c$ are included to show the transfection efficiency of Dnmt1-siRNA; cells transfected with Dnmt1-siRNA had $<50 \%$ Dnmt1 gene and protein expressions compared with the untransfected cells. Dnmt1-siRNA also inhibited
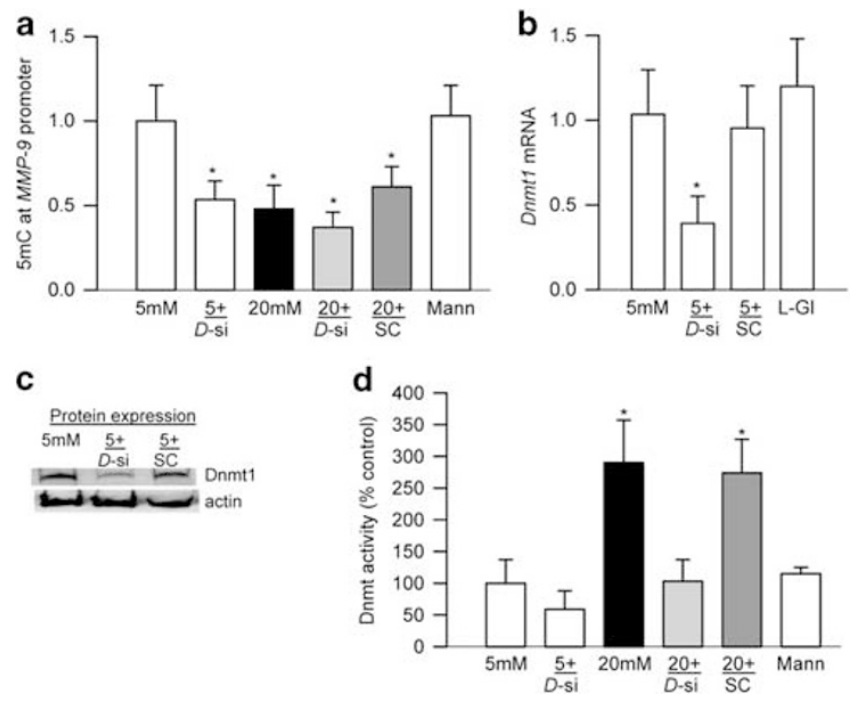

Figure 2 Regulation of DNA methyltransferase ((Dnmt1) has no effect on D-glucose-induced decrease in 5-methylcytosine $(5 \mathrm{mC})$ at the matrix metalloproteinase-9 (MMP-9) promoter. (a) $5 \mathrm{mC}$ levels at the MMP-9 promoter were quantified in the cells transfected with Dnmt1-siRNA or scrambled RNA, and incubated in either $5 \mathrm{mM}$ glucose or $20 \mathrm{mM}$ Dglucose. The transfection efficiency of Dnmt1-siRNA was measured by quantifying Dnmt1 (b) gene transcripts (quantitative real-time PCR (qPCR)) and (c) protein expression (western blot). (d) The activity of Dnmt was assayed in 3-6 $\mu \mathrm{g}$ sample using DNA Methyltransferase Activity/Inhibition Assay Kit, and the values obtained from cells in $5 \mathrm{mM}$ glucose are considered as $100 \%$. Five and $20 \mathrm{mM}=5 \mathrm{mM}$ or $20 \mathrm{mM}$ D-glucose, $5+/ D$-si and $5+/ \mathrm{SC}=$ cells transfected with Dnmt1-siRNA or scrambled RNA, respectively, followed by incubation in $5 \mathrm{mM}$ D-glucose; 20+/D-si and 20 $+/ \mathrm{SC}=$ cells transfected with Dnmt1-siRNA or scrambled RNA, respectively, and incubated in $20 \mathrm{mM}$ D-glucose; Mann $=20 \mathrm{mM}$ mannitol; $\mathrm{L}-\mathrm{Gl}=20 \mathrm{mM}$ L-glucose. Data are represented as mean $\pm \mathrm{s}$.d. from each measurement made in duplicate in three to five cell preparations. ${ }^{*} P<0.05$ compared with $5 \mathrm{mM}$ D-glucose. siRNA, small interfering RNA.

significantly increase in Dnmt enzyme activity, observed in high D-glucose condition (Figure 2d).

Due to the dynamic nature of DNA methylation, methylated cytosine can be converted to $5 \mathrm{hmC} ; 23,24$ to understand the mechanism for decreased $5 \mathrm{mC}$ levels at the MMP-9 promoter, in spite of increased Dnmtl binding, $5 \mathrm{hmC}$ levels were quantified. $5 \mathrm{hmC}$ levels at the MMP-9 promoter were increased by three fold in the cells incubated in high D-glucose compared with the cells in $5 \mathrm{mM}$ D-glucose or $20 \mathrm{mM}$ mannitol (Figure 3a). The role of demethylation in MMP-9 transcription was confirmed by supplementing $20 \mathrm{mM}$ D-glucose medium with an inhibitor of the hydroxymethylation enzymes; addition of $2-\mathrm{HG}$, in addition to preventing glucose-induced increase in Tet activity (Figure 3b), also ameliorated increase in $M M P-9$ transcripts (Figure 3c).

Tet family of enzymes has three major members, Tet1, Tet2, and Tet3;24,30 to determine the specific isoform(s) responsible for hypomethylation of $M M P-9$ promoter, the effect of $20 \mathrm{mM}$ D-glucose on their expressions was 

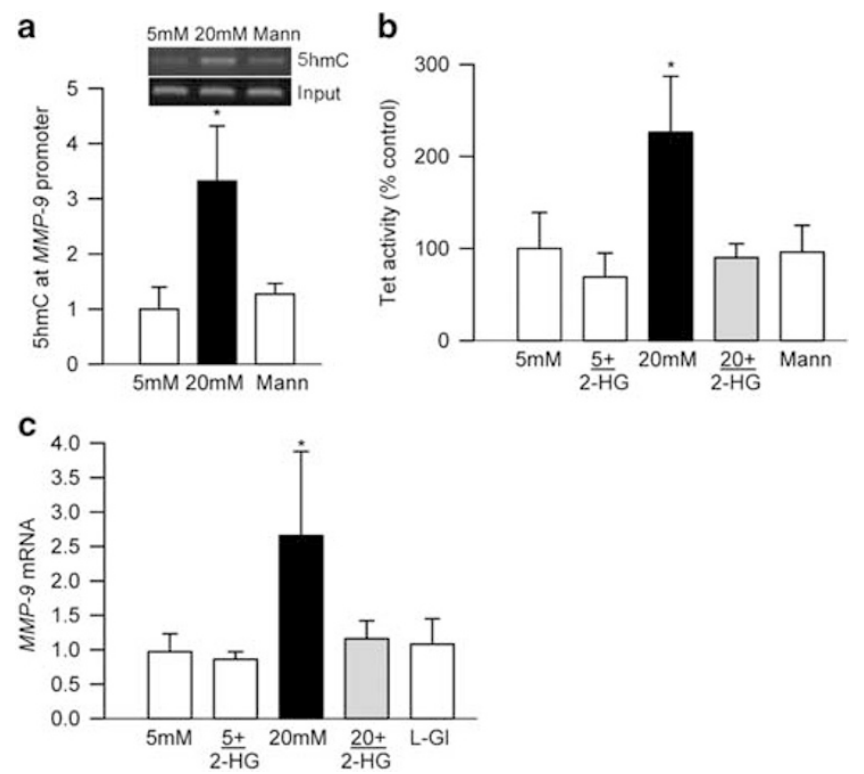

Figure 3 High D-glucose increases hydroxymethylation of matrix metalloproteinase-9 (MMP-9) promoter and Tet activity. (a) The levels of 5 -hydroxymethylcytosine $(5 \mathrm{hmC})$ were quantified in retinal endothelial cells using hMeDIP Immunoprecipitation Kit. (b) The enzyme activity of Tet was determined in 10-20 $\mu \mathrm{g}$ sample using TET Activity/Inhibition Assay Kit, and the values obtained from cells in $5 \mathrm{mM}$ glucose are considered as $100 \%$. (c) MMP-9 mRNA was quantified by quantitative real-time PCR (qPCR). Values are represented as mean \pm s.d. from four to five cell preparations, with each measurement made in duplicate. Five and $20 \mathrm{mM}=5 \mathrm{mM}$ or $20 \mathrm{mM}$ D-glucose; $5+/ 2-\mathrm{HG}$ and $20+/ 2-$ $\mathrm{HG}=$ cells incubated in 5 or $20 \mathrm{mM}$ D-glucose in the presence of $500 \mu \mathrm{M}$ 2-HG; Mann $=20 \mathrm{mM}$ mannitol; $\mathrm{L}-\mathrm{Gl}=$ cells in $20 \mathrm{mM}$ L-glucose. ${ }^{*} P<0.05$ compared with $5 \mathrm{mM}$ D-glucose. $2-\mathrm{HG}$, (2S)-octyl- $\alpha$-hydroxyglutarate.

quantified. Although $20 \mathrm{mM}$ D-glucose had no effect on Tet1 and Tet3, Tet 2 expression (protein and gene) was significantly increased compared with the values obtained from cells in normal glucose (Figure 4a). The role of Tet2 in hydroxymethylation of $5 \mathrm{mC}$ was confirmed by its binding at the MMP-9 promoter using ChIP technique; consistent with increase in $5 \mathrm{hmC}$ levels, Tet2 binding was also elevated by over fourfold in cells incubated in $20 \mathrm{mM}$ D-glucose. In the same samples, IgG controls were $<1 \%$ compared with the values obtained using Tet 2 antibody (Figure $4 \mathrm{~b}$ ). Regulation of Tet 2 by its specific siRNA prevented $20 \mathrm{mM}$ D-glucoseinduced increase in $5 \mathrm{hmC}$ levels, and, surprisingly, ameliorated decrease in $5 \mathrm{mC}$ levels at the MMP-9 promoter. In the same cell preparation, transcriptional activation of MMP-9 was also protected (Figure 5a).

Activated MMP-9 damages retinal mitochondria initiating capillary cell apoptosis, which precedes the development of degenerative capillaries in the retinal microvasculature. ${ }^{4}$ The protective effect of inhibition of hydroxymethylation was confirmed by quantifying transcription of mtDNA. As expected, incubation of cells in $20 \mathrm{mM}$ D-glucose, but not in $20 \mathrm{mM} \mathrm{L-glucose,} \mathrm{significantly} \mathrm{decreased} \mathrm{mtDNA}$
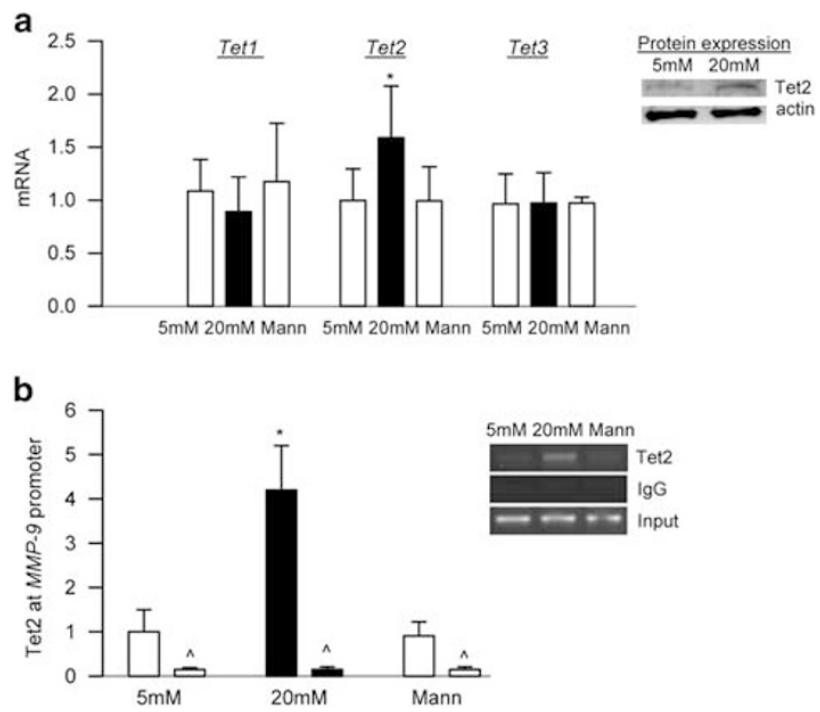

Figure 4 Tet2 expression and its binding at the matrix metalloproteinase9 (MMP-9) promoter are increased by high glucose. (a) The gene transcripts of Tet1, Tet2, and Tet3 were quantified by quantitative realtime PCR (qPCR) using gene-specific primers, and the protein expression of Tet2 was determined by western blot technique using $\beta$-actin as a housekeeping gene (qPCR)/loading control (western blot). (b) Tet2 binding at the MMP-9 promoter was quantified in the Tet2-

immunoprecipitated crosslinked cells using immunoglobulin $\mathrm{G}(\mathrm{lgG})$ as a negative antibody control (indicated as $\wedge$ ), and Ct values were normalized with the values from input by $\mathrm{ddCt}$ method. Values are represented as mean \pm s.d. from three to five samples in each group. Five and $20 \mathrm{mM}=5 \mathrm{mM}$ and $20 \mathrm{mM}$ D-glucose; Mann $=20 \mathrm{mM}$ mannitol. ${ }^{*} P<0.05$ compared with $5 \mathrm{mM}$ D-glucose.

transcription, as depicted by $40-60 \%$ decrease in mtDNAencoded Cytb and ND6. However, regulation of hydroxymethylation ameliorated glucose-mediated decrease in transcription of both Cytb and ND6 (Figure 5b). Figures $5 \mathrm{c}$ and d are included to show the $\sim 50 \%$ decrease in mRNA and protein expression of Tet 2 in the cells transfected with Tet2-siRNA.

\section{Diabetic Animal Model}

Consistent with the results from isolated retinal endothelial cells in high D-glucose, diabetes decreased $5 \mathrm{mC}$ levels in the promoter region $(-640$ to -356$)$ of the retinal MMP-9, compared with the values from nondiabetic normal mice. However, 5mC levels in the intragenic $\mathrm{CpG}$ island region (1361-1600) remained unchanged in the retina from normal and diabetic mice (Figure 6a). As expected, ${ }^{4,9}$ in the same diabetic animals, retinal MMP-9 transcripts were significantly higher compared with those from normal mice (Figure 6b).

Dnmt is activated in the retina in diabetes, ${ }^{20}$ and consistent with the results from diabetic rats and retinal endothelial cells in high D-glucose, among the members of the Dnmt family, the expression of Dnmtl was significantly elevated (Figure 6c). To investigate the role of Dnmtl in the regulation 

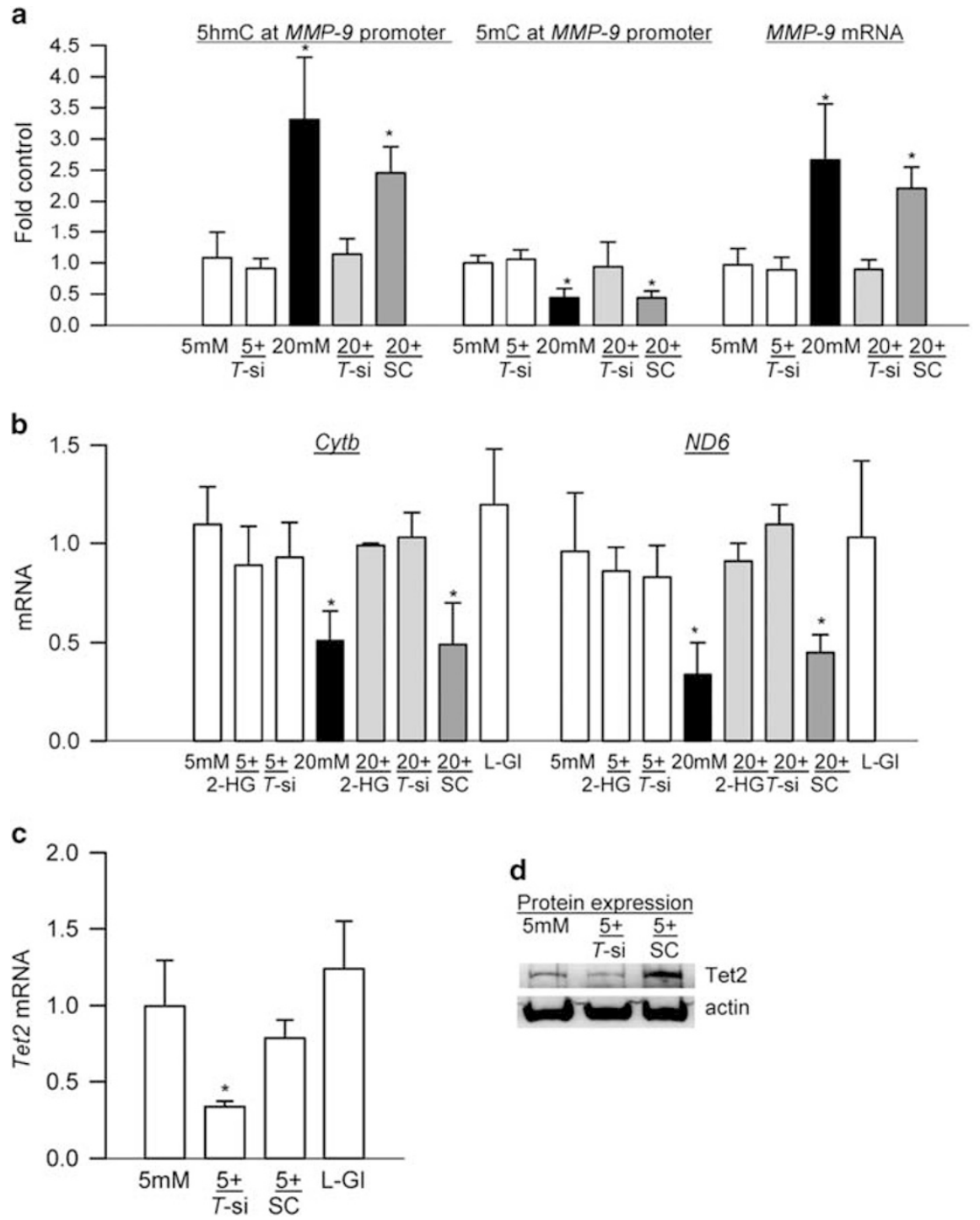

Figure 5 Inhibition of Tet2 by its small interfering RNA (siRNA) ameliorates D-glucose-induced increase in 5-hydroxymethylcytosine (5hmC) and 5methylcytosine ( $5 \mathrm{mC}$ ) levels at the matrix metalloproteinase-9 (MMP-9) promoter, and protects mitochondrial damage. (a) The levels of $5 \mathrm{hmC}$ and $5 \mathrm{mC}$, and MMP-9 mRNA were quantified in the cells transfected with Tet2-siRNA or scrambled RNA. (b) Mitochondrial DNA damage was assessed by quantifying gene transcripts of mitochondrial DNA (mtDNA)-encoded cytochrome b (Cytb) and ND6 by quantitative real-time PCR (qPCR) using $\beta$-actin as the housekeeping gene. Transfection efficiency of Tet2-siRNA was determined by quantifying its (c) gene transcripts and (d) protein expression. Five and $20 \mathrm{mM}=5 \mathrm{mM}$ or $20 \mathrm{mM}$ D-glucose; $5+/ T$-si and $5+/ \mathrm{SC}=$ cells transfected with Tet2-siRNA or scrambled RNA, respectively, followed by incubation in $5 \mathrm{mM}$ D-glucose; $20+/ T$-si and $20+/ \mathrm{SC}=$ Tet2-siRNA or scrambled RNA transfected cells incubated in $20 \mathrm{mM}$ D-glucose; $5+/ 2-\mathrm{HG}$ and $20+/ 2-\mathrm{HG}=$ cells incubated in the presence of $500 \mu \mathrm{M} 2-\mathrm{HG}$ in $5 \mathrm{mM}$ or $20 \mathrm{mM}$ D-glucose respectively; L-Gl $=20 \mathrm{mM}$ L-glucose. Data are represented as mean $\pm \mathrm{s}$.d. from three to five measurement made in duplicate. ${ }^{*} P<0.05$ compared with $5 \mathrm{mM}$ D-glucose. 2-HG, (2S)-octyl-a-hydroxyglutarate.

of retinal MMP-9 promoter methylation status, its binding at the MMP-9 promoter was determined. Figure $6 \mathrm{~d}$ shows a significant increase in Dnmtl binding at the MMP-9 promoter; the values obtained from diabetic mice were over twofold higher compared with the nondiabetic mice. Similar discrepancies between increase in Dnmtl binding but decrease in $5 \mathrm{mC}$ levels at the MMP-9 promoter by high glucose in retinal endothelial cells and in the retina from diabetic mice support an active demethylation of the MMP-9 promoter.
To further confirm the role of active hypomethylation in transcriptional activation of MMP-9 in diabetes, $5 \mathrm{hmC}$ levels were quantified; as shown in Figure $7 \mathrm{a}, 5 \mathrm{hmC}$ levels at the MMP-9 promoter were increased by over 2.5 -fold in the retina from diabetic mice compared with that from age-matched normal mice. In the same retina samples, global Tet activity was also elevated by $\sim 75 \%$ (Figure $7 \mathrm{~b}$ ), and among the three members of Tet family, only Tet2 expression (mRNA and protein) showed significant increase in the retina from diabetic mice compared with the retina from 
a

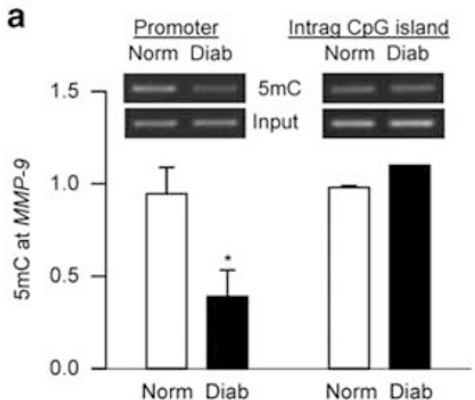

b

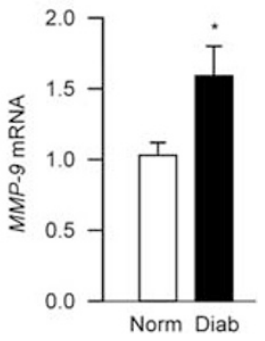

c
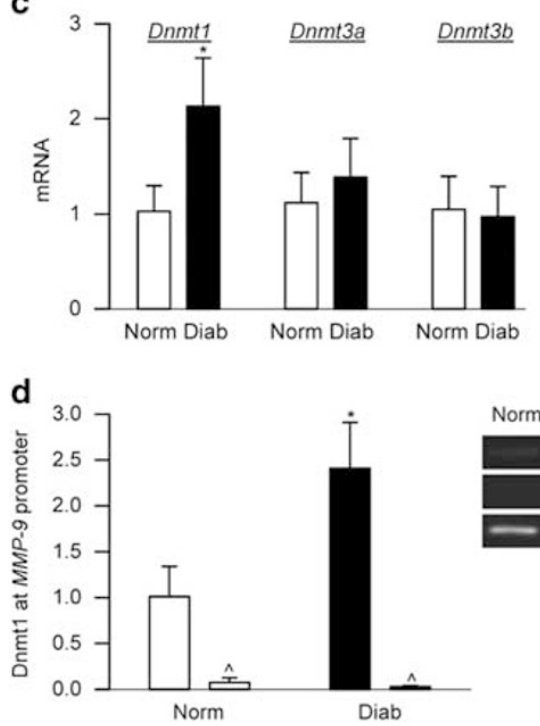

Figure 6 Diabetes hypomethylates matrix metalloproteinase-9 (MMP-9) promoter, but the binding of DNA methyltransferase (Dnmt1) in the same region is increased. (a) The levels of 5-methylcytosine $(5 \mathrm{mC})$ were quantified in the promoter (-640 to -356$)$ and the intragenic CpG island (1361-1600) regions of the MMP-9 gene by methylated DNA Immunoprecipitation Kit. Total genomic DNA obtained from normal mouse retina served as input DNA control. Gene transcripts of (b) MMP-9, and (c) Dnmts were quantified by SYBR green-based quantitative realtime PCR (qPCR) using $\beta$-actin as the housekeeping gene. (d) The binding of Dnmt1 at the MMP-9 promoter region was measured in the crosslinked retina by immunoprecipitating the samples with Dnmt1 antibody, followed by amplification of the promoter region by $\mathrm{qPCR}$.

Immunogobulin G (IgG) was used as a negative antibody control (indicated as $\wedge$ ), and $\mathrm{Ct}$ values were normalized with the values from input by $\mathrm{ddCt}$ method. Values are represented as mean \pm s.d. from five to seven mice in each group. Norm and Diab = retina from nondiabetic normal mouse or from diabetic mouse respectively. ${ }^{*} P<0.05$ compared with normal.

nondiabetic mice (Figure 7c). Diabetes also elevated Tet2 binding at the MMP-9 promoter by over threefold (Figure 7d), further confirming the role of Tet-mediated hypomethylation in MMP-9 transcriptional activation in diabetes.

\section{DISCUSSION}

Diabetes alters expressions of genes implicated in the metabolic abnormalities including genes encoding proteins

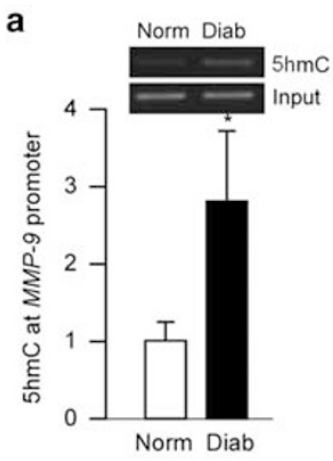

b
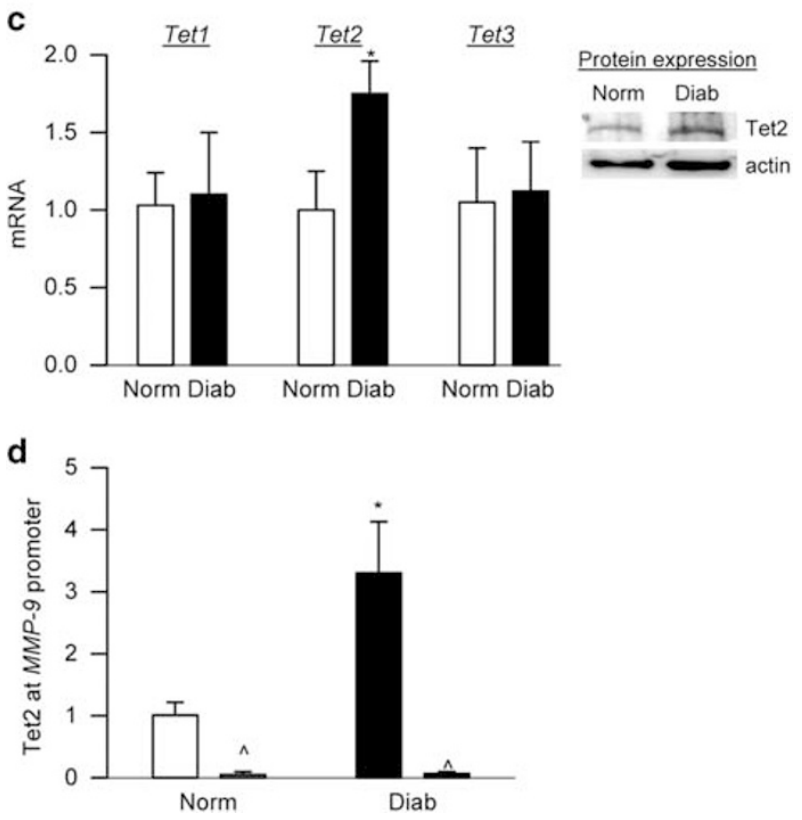

Figure 7 The levels of 5-hydroxymethylcytosine $(5 \mathrm{hmC})$ are increased at the retinal matrix metalloproteinase-9 (MMP-9) promoter in diabetes, and hydroxymethylation enzyme machinery is activated. (a) $5 \mathrm{hmC}$ levels were quantified at the promoter region in sonicated DNA using hMeDIP Immunoprecipitation Kit. The total genomic DNA obtained from normal mouse retina was used as an input DNA control. (b) The enzyme activity of Tet was measured in 10-20 $\mu \mathrm{g}$ retina using TET Activity/Inhibition Assay Kit and the values obtained from the normal mouse retina are considered as $100 \%$, (c) The gene transcripts of Tet1, Tet2, and Tet3 were quantified SYBR green-based quantitative real-time PCR (qPCR), and the protein expression of Tet2 was determined by western blot technique. $\beta$ Actin was used as a housekeeping gene (qPCR)/loading control (western blot). (d) Binding of Tet2 at the MMP-9 promoter was determined in the Tet2-immunoprecipitated crosslinked retina using immunoglobulin $\mathrm{G}(\lg \mathrm{G})$ as a negative antibody control (indicated as $\wedge$ ). Data are represented as mean \pm s.d. from six to seven mice in each group, with each measurement made in duplicate. ${ }^{*} P<0.05$ compared with normal.

for mitochondrial biogenesis and proinflammatory cytokines. ${ }^{3,31,32}$ MMP-9 expression and mitochondrial accumulation are elevated in the retina and its capillary cells in diabetes, and increased MMP-9 damages mitochondrial membrane, activating the apoptotic machinery, a phenomenon that precedes the development of diabetic retinopathy. $4,7,9,33,34$ Although gene expression is mainly 
modulated by the transcriptional factors, it can also be regulated by metabolite fluctuations, and these epigenetic modifications alter gene expression without altering the DNA sequence. ${ }^{11,35}$ We have shown that in the pathogenesis of diabetic retinopathy, histones in the retinal MMP-9 promoter are epigenetically modified, increasing the binding of NF- $\kappa \mathrm{B}$ and AP-1. ${ }^{6,9,34}$ Here, our exciting data obtained from both in vitro (retinal capillary cells that are the target of histopathology characteristic of diabetic retinopathy) and in vivo (retina from diabetic rodents) models show that the hyperglycemic milieu also alters the methylation status of MMP-9 promoter. Despite decreased $5 \mathrm{mC}$ in the promoter region, the binding of the Dnmtl is increased, but a concomitant activation of the demethylation machinery keeps the MMP-9 promoter hypomethylated, resulting in its increased transcription. Silencing of the cytosine hydroxymethylation enzyme Tet2 prevents hyperglycemia-induced increase in $5 \mathrm{hmC}$ and $M M P-9$ transcription, and maintains mitochondrial homeostasis. These results clearly suggest that in diabetes active cytosine methylation-demethylation process of the MMP-9 promoter has a significant role in its transcriptional activation, and regulation of the cytosine methylation-demethylation machinery could inhibit the development/progression of diabetic retinopathy by preventing MMP-9-mediated mitochondrial damage.

Aberrant DNA methylation is considered as an important mechanism of gene regulation. In normal cells, DNA methylation is associated with organization of chromatin into active and inactive state, regulation of gene expression, and tissue-specific expression and genomic imprinting. ${ }^{36,37}$ DNA methylation often represses gene transcription by interfering with the binding of the transcription factor, and/or recruitment of other factors to form repression complex. ${ }^{38}$ The process acts as an interplay between external factors and genome, and is affected by many external factors including drugs and disease severity. ${ }^{10,24}$ MMP-9 promoter has relatively few $\mathrm{CpG}$ islands, but it contains many $\mathrm{CpG}$ sites; ${ }^{27,28}$ the results presented here show that diabetes decreases $5 \mathrm{mC}$ levels in the promoter region of retinal $M M P$-9. Although methylation of the intragenic $\mathrm{CpG}$ islands can also regulate the gene expression, ${ }^{39}$ we show that hyperglycemia has no effect on the intragenic region of the MMP-9 gene, suggesting that DNA methylation of the promoter is critical in regulating its transcription. The promoter regions used in our study includes the binding sites of the transcription factors essential for MMP-9 transcription, such as $\mathrm{NF}-\kappa \mathrm{B}$ and $\mathrm{Sp} 1$, and reduced $5 \mathrm{mC}$ levels in this region indicate that hypomethylation of this region could be favoring the recruitment of these transcriptional factors. Consistent with this, hypomethylation of MMP-9 promoter in other tissues is shown to influence the binding of NF- $\kappa \mathrm{B}$, and regulate its active transcription, ${ }^{27,28}$ and in diabetes, the binding of NF- $\kappa \mathrm{B}$ and AP-1 is increased at the retinal MMP-9 promoter. $^{34}$ The possibility that hypomethylation of MMP-9 promoter could be repressing the binding of the repressor proteins methyl-CpG-binding protein-2, which can interfere with the transcription machinery by binding to methyl-CpG pair, ${ }^{40}$ however, cannot be ruled out.

Despite hypomethylation of MMP-9 promoter, to our surprise, the binding of Dnmtl is significantly elevated at the same region, and regulation of Dnmt1 by its siRNA further decreases $5 \mathrm{mC}$ levels at the MMP-9 promoter. These results clearly support concomitant activation of a demethylation process. Activation of demethylation is further supported by our data showing increased activity of the hydroxymethylating enzyme in the retina, elevated $5 \mathrm{hmC}$ levels in the same region of the MMP-9 promoter, and amelioration of glucoseinduced increase in MMP-9 transcription by Tet inhibitor. Thus, although activation of Dnmt increases its binding, concurrent activation of the hydroxymethylation machinery keeps MMP-9 promoter hypomethylated, facilitating the transcription process. In support, others have shown an inverse correlation between DNA methylation and MMP-9 transcription in mouse thymic lymphoma cell line. ${ }^{27}$ Although Tet family has three major members, ${ }^{24,30}$ we show that in diabetes Tet 2 is the most affected member in the retina and its capillary cells. The role of Tet2 in regulating active demethylation of the MMP-9 promoter is further confirmed by its increased binding at the same promoter region, and also by its siRNA, which, in addition to preventing glucoseinduced increase in $5 \mathrm{hmC}$, also prevents decrease in $5 \mathrm{mC}$ and protects increase in MMP-9. Amelioration of diabetesinduced increase in mtDNA damage and decrease in its transcription further confirms the role of Tet in diabetic retinopathy. We recognize that although demethylation could be initiated and processed by multiple pathways including passive dilution and deamination, ${ }^{23,24}$ capillary cells do not actively proliferate after birth, abating the possibility of a replication-dependent passive dilution assisting in the loss of methylation of the MMP-9 promoter seen here in the retinal endothelial cells. Our in vivo experiments were performed in the retina, a complex tissue with multiple layers and cell type; however, similar results from retinal endothelial cells in culture and retina from diabetic rodents support retinal MMP-9 regulation in diabetes by a dynamic DNA methylation process.

The present study is focused on DNA methylationdemethylation of the MMP-9 promoter; however, hypomethylation of $\mathrm{H} 3 \mathrm{~K} 9$ is also observed in diabetes, and this frees up that lysine 9 of $\mathrm{H} 3 \mathrm{~K} 9$ for acetylation, facilitating the recruitment of NF- $\kappa \mathrm{B} .{ }^{9}$ Consistent with multiple epigenetic modifications seen in the retinal MMP-9 promoter in diabetes, others have shown correlation among broad changes in $\mathrm{H} 3 \mathrm{~K} 9$ acetylation by high glucose, DNA hypomethylation and gene induction. ${ }^{36}$ Furthermore, MMP-9 is also regulated by its intracellular tissue inhibitor, TIMP-1, whose levels are decreased in the retina in diabetes; ${ }^{5}$ thus, its role in regulating retinal MMP-9 activity cannot be ruled out. 
Recent studies have suggested that $5 \mathrm{hmC}$ is critical in various important normal processes, such as ion transport, transcription, cell adhesion, and cell death, ${ }^{23,41}$ and it is now considered not only as an intermediate in demethylation but also as an independent epigenetic marker whose altered levels are observed in many chronic diseases including cancer and Rett syndrome. ${ }^{41,42}$ Tet activation is being implicated in many diseases, including diabetic complications, Alzheimer's, and liver cancer. ${ }^{24,26,38,43,44}$ Hyperglycemia in zebrafish activates $\mathrm{Tet}^{26}$ and induces a genome-wide demethylation and aberrant gene expression. ${ }^{45}$ Site-specific demethylation of MMP-9 promoter is shown to have an important role in the pathogenesis of diabetic refractory ulcers, ${ }^{28}$ and here, we show that the regulation of hypomethylation of retinal $M M P-9$ promoter regulates its transcription and prevents mitochondrial damage. MMP-9 has important role in the pathogenesis of diabetic retinopathy, and mice with MMP-9 gene regulated are protected from the development of diabetic retinopathy, $4,33,34$ thus suggesting that the regulation of methylation of MMP-9 could serve as an important target in maintaining mitochondrial homeostasis, and the development of diabetic retinopathy.

\section{ACKNOWLEDGMENTS}

We thank Mangayarkarasi Thandampallayam Ajjeya for her help with the maintenance of animal colony. This study was supported, in part, by grants from the National Institutes of Health (EY014370, EY017313, and EY022230) and from the Thomas Foundation (to RAK), and an unrestricted grant to the Ophthalmology Department from Research to Prevent Blindness.

\section{DISCLOSURE/CONFLICT OF INTEREST}

The authors declare no conflict of interest.

1. Kowluru RA, Abbas SN. Diabetes-induced mitochondrial dysfunction in the retina. Invest Ophthalmol Vis Sci 2003;44:5327-5334.

2. Kanwar M, Chan PS, Kern TS, et al. Oxidative damage in the retinal mitochondria of diabetic mice: possible protection by superoxide dismutase. Invest Ophthalmol Vis Sci 2007;48:3805-3811.

3. Kowluru RA, Kowluru A, Mishra M, et al. Oxidative stress and epigenetic modifications in the pathogenesis of diabetic retinopathy. Prog Retin Eye Res 2015;48:40-61.

4. Kowluru RA, Mohammad G, dos Santos JM, et al. Abrogation of MMP-9 gene protects against the development of retinopathy in diabetic mice by preventing mitochondrial damage. Diabetes 2011;60:3023-3033.

5. Santos JM, Tewari S, Lin JY, et al. Interrelationship between activation of matrix metalloproteinases and mitochondrial dysfunction in the development of diabetic retinopathy. Biochem Biophys Res Commun 2013;438:760-764.

6. Kowluru RA, Santos JM, Zhong Q. Sirt1, a negative regulator of matrix metalloproteinase-9 in diabetic retinopathy. Invest Ophthalmol Vis Sci 2014;55:5653-5660.

7. Kern TS, Tang J, Mizutani M, et al. Response of capillary cell death to aminoguanidine predicts the development of retinopathy: comparison of diabetes and galactosemia. Invest Ophthalmol Vis Sci 2000;41: 3972-3978.

8. Hsieh MJ, Lin CW, Yang SF, et al. Glabridin inhibits migration and invasion by transcriptional inhibition of matrix metalloproteinase 9 through modulation of NF-kB and AP-1 activity in human liver cancer cells. Br J Pharmacol 2014;171:3037-3050.

9. Zhong Q, Kowluru RA. Regulation of matrix metalloproteinase-9 by epigenetic modifications and the development of diabetic retinopathy. Diabetes 2013;62:2559-2568.
10. Ling C, Groop L. Epigenetics: a molecular link between environmental factors and type 2 diabetes. Diabetes 2009;58:2718-2725.

11. Villeneuve LM, Reddy MA, Natarajan R. Epigenetics: deciphering its role in diabetes and its chronic complications. Clin Exp Pharmacol Physiol 2011;38:401-409.

12. Jones PA. Functions of DNA methylation: islands, start sites, gene bodies and beyond. Nat Rev Genet 2012;13:484-492.

13. Robertson KD, Wolffe AP. DNA methylation in health and disease. Nat Rev Genet 2000;1:11-19.

14. Nasonkin IO, Lazo K, Hambright D, et al. Distinct nuclear localization patterns of DNA methyltransferases in developing and mature mammalian retina. J Comp Neurol 2011;519:1914-1930.

15. Wahlin KJ, Enke RA, Fuller JA, et al. Epigenetics and cell death: DNA hypermethylation in programmed retinal cell death. PLoS One 2013;8: e79140.

16. Yan B, Yao J, Tao ZF, et al. Epigenetics and ocular diseases: from basic biology to clinical study. J Cell Physiol 2013;229:825-833.

17. Kowluru RA, Santos JM, Mishra M. Epigenetic modifications and diabetic retinopathy. Biomed Res Int 2013;2013:635284.

18. He S, Li X, Chan N, et al. Review: epigenetic mechanisms in ocular disease. Mol Vis 2013;19:665-674.

19. Tewari S, Zhong Q, Santos JM, et al. Mitochondria DNA replication and DNA methylation in the metabolic memory associated with continued progression of diabetic retinopathy. Invest Ophthalmol Vis Sci 2012;53: 4881-4888.

20. Mishra M, Kowluru RA. Epigenetic modification of mitochondrial DNA in the development of diabetic retinopathy. Invest Ophthalmol Vis Sci 2015;56:5133-5142.

21. Guibert $S$, Forne $T$, Weber M. Dynamic regulation of DNA methylation during mammalian development. Epigenomics 2009;1: 81-98.

22. Majumdar S, Buckles E, Estrada J, et al. Aberrant DNA methylation and prostate cancer. Curr Genomics 2011;12:486-505.

23. Tahiliani $\mathrm{M}$, Koh KP, Shen $\mathrm{Y}$, et al. Conversion of 5 -methylcytosine to 5-hydroxymethylcytosine in mammalian DNA by mll partner tet1. Science 2009;324:930-935.

24. Kohli RM, Zhang Y. Tet enzymes, tdg and the dynamics of DNA demethylation. Nature 2013;502:472-479.

25. Wu H, Zhang Y. Reversing DNA methylation: mechanisms, genomics, and biological functions. Cell 2014;156:45-68.

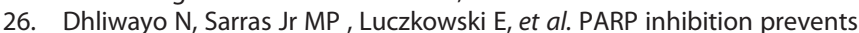
ten-eleven translocase enzyme activation and hyperglycemia-induced DNA demethylation. Diabetes 2014;63:3069-3076.

27. Chicoine E, Esteve PO, Robledo O, et al. Evidence for the role of promoter methylation in the regulation of MMP-9 gene expression. Biochem Biophys Res Commun 2002;297:765-772.

28. Ling L, Ren M, Yang C, et al. Role of site-specific DNA demethylation in Tnf alpha-induced MMP-9 expression in keratinocytes. J Mol Endocrinol 2013;50:279-290.

29. $\mathrm{Xu} \mathrm{W}$, Yang $\mathrm{H}$, Liu $\mathrm{Y}$, et al. Oncometabolite 2-hydroxyglutarate is a competitive inhibitor of alpha-ketoglutarate-dependent dioxygenases. Cancer Cell 2011;19:17-30.

30. Williams K, Christensen J, Pedersen MT, et al. Tet1 and hydroxymethylcytosine in transcription and DNA methylation fidelity. Nature 2011;473:343-348.

31. Kern TS. Contributions of inflammatory processes to the development of the early stages of diabetic retinopathy. Exp Diabetes Res 2007;2007:95103.

32. Kowluru RA. Mitochondria damage in the pathogenesis of diabetic retinopathy and in the metabolic memory associated with its continued progression. Curr Med Chem 2013;20:3226-3233.

33. Kowluru RA, Zhong Q, Santos JM. Matrix metalloproteinases in diabetic retinopathy: potential role of $\mathrm{mmp}-9$. Expert Opin Investig Drugs 2012;21:797-805

34. Mishra M, Flaga J, Kowluru RA. Molecular mechanism of transcriptional regulation of matrix metalloproteinase- 9 in diabetic retinopathy. J Cell Physiol 2016;231:1709-1718.

35. Deaton AM, Bird A. Cpg islands and the regulation of transcription. Genes Dev 2011;25:1010-1022.

36. Pirola L, Balcerczyk A, Okabe J, et al. Epigenetic phenomena linked to diabetic complications. Nat Rev Endocrinol 2010;6:665-675.

37. Gemenetzi M, Lotery AJ. The role of epigenetics in age-related macular degeneration. Eye (Lond) 2014;28:1407-1417. 
38. Kato M, Natarajan R. Diabetic nephropathy-emerging epigenetic mechanisms. Nat Rev Nephrol 2014;10:517-530.

39. Medvedeva YA, Fridman MV, Oparina NJ, et al. Intergenic, gene terminal, and intragenic cpg islands in the human genome. BMC Genomics. 2010;11:48.

40. Nan X, Ng HH, Johnson CA, et al. Transcriptional repression by the methyl-cpg-binding protein Mecp2 involves a histone deacetylase complex. Nature 1998;393:386-389.

41. Yang $\mathrm{H}$, Liu $\mathrm{Y}$, Bai $\mathrm{F}$, et al. Tumor development is associated with decrease of tet gene expression and 5-methylcytosine hydroxylation. Oncogene 2013;32:663-669.
42. Wang J, Tang J, Lai $M$, et al. 5-Hydroxymethylcytosine and disease Mutat Res Rev Mutat Res 2014;762:167-175.

43. Liu ZZ, Zhao XZ, Zhang XS, et al. Promoter DNA demethylation of keap1 gene in diabetic cardiomyopathy. Int J Clin Exp Pathol 2014;7: 8756-8762.

44. Li D, Guo B, Wu H, et al. Tet family of dioxygenases: crucial roles and underlying mechanisms. Cytogenet Genome Res 2015;146:171-180.

45. Olsen AS, Sarras MP, Leontovich A, et al. Heritable transmission of diabetic metabolic memory in zebrafish correlates with DNA hypomethylation and aberrant gene expression. Diabetes 2012;61: 485-491. 